\title{
Mikro Şerit Dizi Anten için Besleme Ağı Tasarımı ve Uygulanması
}

\author{
Gökhan SATILMIŞ ${ }^{1 *}$, Filiz GÜNEŞ ${ }^{2}$ \\ ${ }^{1}$ Muş Alparslan Üniversitesi, Elektrik-Elektronik Mühendisliği Bölümü, Muş \\ ${ }^{2}$ Yıldız Teknik Üniversitesi, Elektronik ve Haberleşme Mühendisliği Bölümü, İstanbul
}

\begin{abstract}
$\ddot{O} z$
$\mathrm{Bu}$ çalışmada Ku alt frekans bandında mikro șerit dizi anten için eș genlikli ve eș faz olacak șekilde bir besleme ağı yapısı ortaya konmuştur. Besleme ağı $8 \times 4$ toplam 32 elemanı besleyecek şekilde paralel besleme ağı kullanılarak tasarlanmıștır. Paralel besleme ağı her bir birim antene eş faz sağlaması ve anten dizisinin ışıma paterninde geniş tarafı öne gelecek şekilde ışıma yapması sağlanmıştır. Besleme ağı yapısı yaklaşık 1 desibellik bir uyumsuzlukla her bir antene güç paylaşımı sağlamayı başarmıştır. Besleme ağının gerçek performansını sağlamak için anten dizisiyle birleştirilmesi gerekmektedir. Bunun için açıklık kuplaj ile beslenen mikro şerit birim anten en uygun kazanç, yan lob seviyesi, bant genişliği ve empedans uyumu olacak şekilde tasarlanmıştır. Tasarımlanan besleme ağı yapısı 32 elemanlı birim anten dizisiyle birleştirilmiştir. Sonuç olarak besleme ağı ve anten dizisi birleştirilmesiyle sistemin bant genişliği, kazancı ve giriş uyumsuzluk değeri istenilen seviyeye gelmiştir. Besleme ağı ve anten dizisinin 3 boyutlu olarak alttan ve üstten gösterimi verilmiştir.
\end{abstract}

Anahtar kelimeler: Mikro Şerit Dizi Anten, Besleme Ağı, Seri ve Paralel Besleme, Açıklık Kuplaj

\section{Feed Network Design and Application for Micro strip Antenna Arrays}

\begin{abstract}
In this paper, a feed network which feeds antenna arrays with equal phase and magnitude operating lower Ku frequency band is presented. The feed network is designed in parallel for feeding 32 unit antenna, so the radiation of antenna array is broadside. Equal power is delivered to the antennas with a $1 \mathrm{~dB}$ mismatch. The feed network is joined with micro strip antenna arrays in order to estimate the real performance and unit antenna is designed to be fed by aperture coupling method. As a conclusion, antenna gain, bandwidth and input impedance mismatch requirements are met and antenna arrays, feed network are depicted in 3D view.
\end{abstract}

Keywords: Micro strip Antenna Arrays, Feed Network, Series and Parallel Feeding, Aperture Coupling

\section{Giriş}

Bu makalede mikro şerit dizi anten tasarımı için besleme ağı yapıları incelenmiştir. Besleme ağı, mikro şerit dizi anten tasarımı gerçekleştirildikten sonra tasarıma eklenir. Mikro şerit dizi anten yapısını daha iyi açıklamak adına birim eleman olan mikro şerit anten incelenmelidir. Kısaca mikro şerit antenlerin avantajlarını şu şekilde sıralayabiliriz[1]:

- Düşük görüntülü yapılara sahip olduğu için aerodinamik yapıyı bozmazlar.

- Düzlemsel veya düzlemsel olmayan yüzeylere yerleştirilebilir.

- Modern devre bask1 teknolojisiyle ucuz olarak üretilebilir.

- Çok amaçlı olarak giriş empedansı, polarizasyonu, tınlaşım frekansı ve ışıma paterni elde edilebilir.

- Mikrodalga tümleşik devre tasarımına uyumludur.

Benzer şekilde dezavantajlarında şu şekilde sıralayabiliriz:

- İletkenlik ve dielektrik kayıpları açısından düşük verimliliğe sahiptir.

*Sorumlu yazar: gokhan.satilmis@gmail.com

Geliş Tarihi: 06/12/2017 Kabul Tarihi: 28/05/2018 
- Düşük güç kapasitesine sahiptir.

- Genel olarak dar bantta ışınım yaparlar.

Birim anten olarak nitelendirilen mikro şerit anten yapısı Şekil 1'de gösterilmiştir ve 3 farklı şekilde beslenebilir.

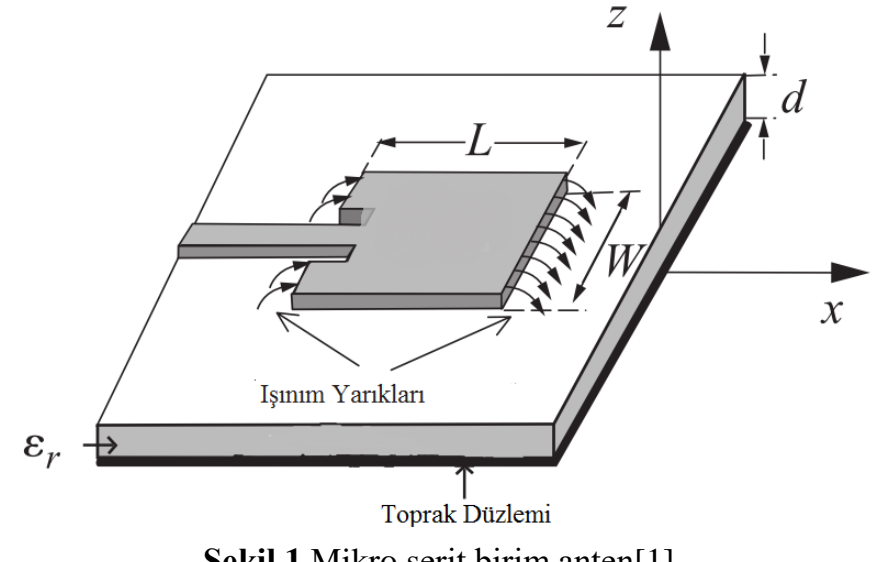

Şekil 1 Mikro şerit birim anten[1]

Besleme yöntemleri mikro şerit besleme, kuplaj yoluyla besleme, koaksiyel besleme, subsratla birleştirilmiş dalga kılavuzuyla besleme[2] ve proksimiti kuplajdır. Doğal olarak dar bant yapıya sahip mikro şerit antenlerin frekans bandını artırmak için yığın yapılar kullanılır. Örnek olarak toprak düzlemiyle ışınım yarıkları arasına köpük doldurulabilir. Açıklık kuplaj besleme yöntemi ile antenler beslenerek geniş bantlı ve yüksek kazançlı anten dizileri gerçekleştirilebilir.[3]

\section{Mikro Şerit Anten Besleme Yöntemleri}

Bahsedilen besleme yöntemleri arasından açıklık kuplaj yöntemi uygulanmıştır. Bu yöntem üretim açısından en zor olmasına rağmen modellemek açısından diğerlerine göre daha kolay ve istenmeyen 1şımalar daha azdır. Açıklık kuplaj yöntemi iki subsratın toprak düzlemiyle ayrılması ile gerçekleşir. Alt tarafta mikro şerit besleme ağı bulunur ve bu sayede besleme tarafindan gelen enerji toprak düzlemindeki yarıklar vasıtasıyla ışıma yapan yama kısmına iletilir. Bu mekanizma besleme hattını ve anten kısmını ayrı şekilde optimizasyon yapılmasına olanak sağlar. Genel olarak, yüksek dielektrik katsayısına sahip subsratı alt katmanda, kalın ve düşük dielektrik katsayısına sahip subsratı ise üst kısım için seçilir. Toprak düzlemi iki subsratı birbirinden izole ettiği için girişimleri ve istenmeyen ışınımları minimize eder.

Anten giriş empedansı ile besleme hattı arasındaki empedans uyumlaştırma genel olarak besleme hattının genişliğini ve yarık uzunluğu en uygun şekle sokarak elde edilir. Şekil 2 de açıklık kuplaj beslemeli birim anten gösterilmiştir.

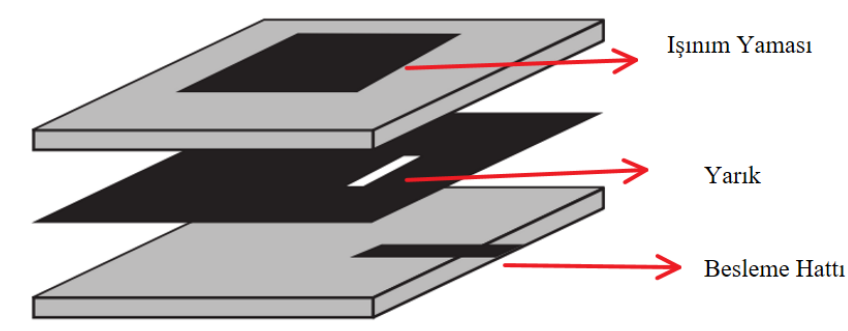

Şekil 2. 3 Boyutlu Açıklık Kuplaj Besleme Gösterimi[3]

\section{Besleme ağı yöntemleri}

Besleme hattından kaynaklanan 1şınımlar ne tür besleme yöntemi kullanılırsa kullanılsın anten performansını etkiler. Örnek olarak çapraz kutuplaşma ve yan lob seviye değerleri verilebilir. Bu tür 1şımaları önlemek ve performansı artırmak için besleme ağı ve ışınım yapan yama birbirinden izole edilmelidir. Anten dizileri paralel, seri ve hibrit olarak beslenebilir ve her bir besleme yöntemin özellikleri farklıdır. Bunun için uygulama özelinde besleme ağı yöntemi seçilmelidir. 


\subsection{Paralel Besleme}

Paralel besleme güç bölücü devre olarak da düşünülebilir. Genellikle tapered hatlar veya çeyrek dalga empedans dönüştürücüleri vasıtasıyla tasarlanabilir. Bu besleme yönteminde tasarımcı her bir antenin besleme genliği ve fazı üzerinde diğerlerine göre daha fazla kontrol sahibidir. 1x4 elemanlı bir anten dizisi için paralel besleme yöntemi gerçekleştirilmiştir[4]. 4x4 elemanlı anten dizisi için de paralel besleme yöntemi kullanılmıştır[5]. Çok ışın demetli antenler, faz kaydırmalı dizi antenler ve şekillendirilmiş ışın demetli anten uygulamaları için bu yöntem kullanılabilir.

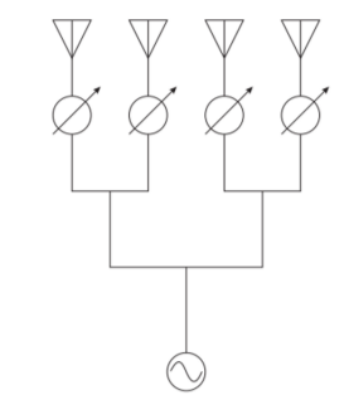

Şekil 3. Paralel Beslenme

\subsection{Seri Besleme}

$\mathrm{Bu}$ tip besleme sabit huzme istenilen anten dizileri veya taramayı frekans değişimi ile gerçekleştiren anten dizileri için kullanılabilir. $1 \mathrm{x} 4$ dizilimine sahip dar bantlı uygulamalar için anten ve besleme ağ yapıs1 optimize edilmiştir[6]. Bu besleme yöntemindeki en kritik nokta besleme hattında gerçekleştirdiğimiz bir değişim diğer antenlerin performansını etkilemesidir.

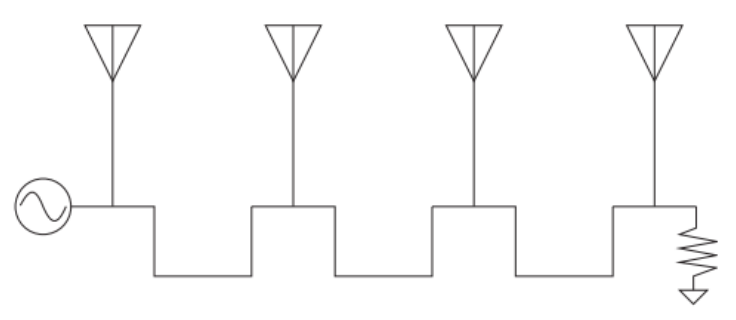

Şekil 4. Seri Besleme

\section{32 Elemanlı Besleme Ağı Tasarımı Ve Anten Dizisiyle Beslenmesi}

Seri ve paralel besleme ağlarının birlikte kullanılarak oluşturulan $8 \times 10$ dizilimine sahip dizi anten yapısı gerçekleştirilmiştir [7]. 32 Elemanlı bir besleme ağında her bir birim antene eş faz ve eş genlik iletilecek şekilde iletilmesi için paralel besleme uygun olacaktır. Çizilen devrede toplam 33 adet port vardır. $\mathrm{Bu}$ portlardan $\left|S_{11}\right|$ 'in genliği giriş yansıma kaybı olarak nitelendirilir ve genel olarak -10 Desibel (dB) değerinden daha küçük olması beklenir. Diğer 32 adet porta gelen sinyalin genliği;

$$
\left|\mathrm{S}_{\mathrm{x} 1}\right|, \quad x=2,3,4 \ldots 32
$$

Şeklinde gösterilebilir. Bu S parametrelerinin değerlerini eş güç paylaşımı varsayarak aşağıdaki denklemden elde edebiliriz.

$$
10 \log (1 / 32)=-15.06 d B
$$

Şekil 5'deki grafikte gösterildiği gibi giriş yansıma kaybının -10 (dB) değerinin istenilen frekans bandı boyunca sağlandığı gözükmektedir. Benzer olarak diğer portlara iletilen sinyalinde yaklaşık olarak 1 $(\mathrm{dB})^{\prime}$ lik bir uyumsuzlukla eşit olarak iletilmesi başarılmıştır. 


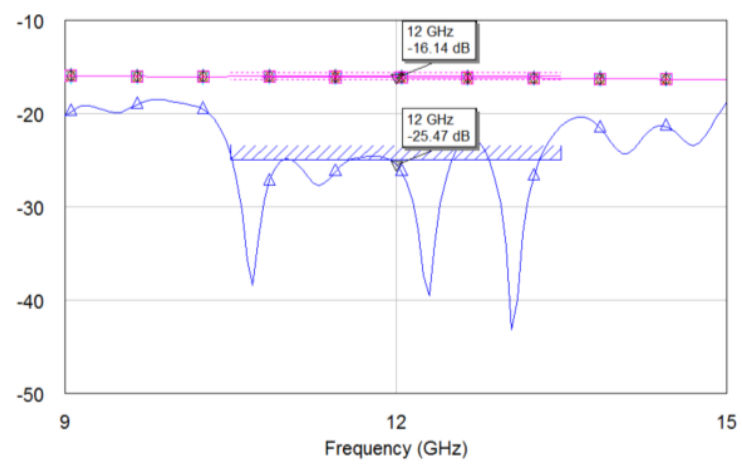

Şekil 5. 33 Portlu Devrenin S Parametrelerinin Genliği

Bir diğer amaçsa her birim antene eş faz iletilecek şekilde bir besleme tasarımıdır. Eş faz ve eş genliği sağlamak için paralel yapılı bir besleme ağı tasarlanmıştır. Kısaca her bir antene iletilen sinyalin açısının eş olabilmesi için;

$$
\text { Angle }\left(\left|S_{21}\right|\right)=\operatorname{Angle}\left(\left|S_{x 1}\right|\right), \quad x=2,3,4 \ldots 32
$$

Yukarıdaki şart sağlanmalıdır. Bu eşitliğin sağlandığı Şekil 6'deki grafikte gözükmektedir. Tasarım olarak geniş tarafı öne gelecek şekilde ışıma amaçlandığı için her bir antene eş faz gitmesi önemlidir. Eş faz iletilmediği takdirde dizi antenin ana lobu bir yöne doğru eğilebilir ve bu da haberleşmenin performansını direk olarak etkiler.

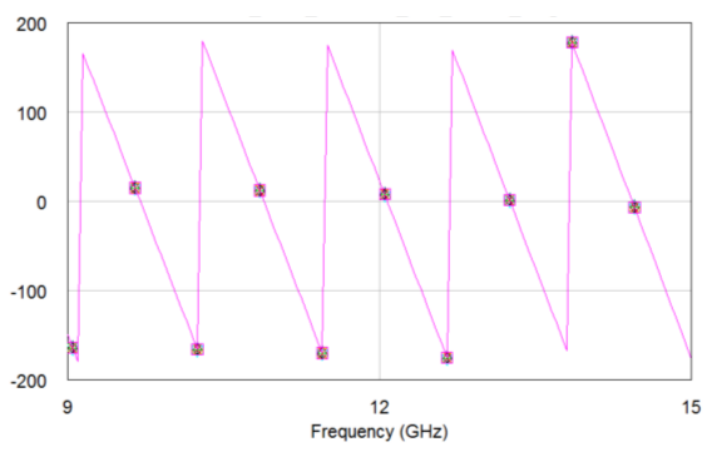

Şekil 6. 33 Portlu Devrenin S Parametrelerinin Açısı

Yatay eksende 4 ve düşey eksende 8 tane olmak üzere anten dizisinin alttan ve üstten görünüşleri şekil 7 ve 8 de gösterilmiştir.

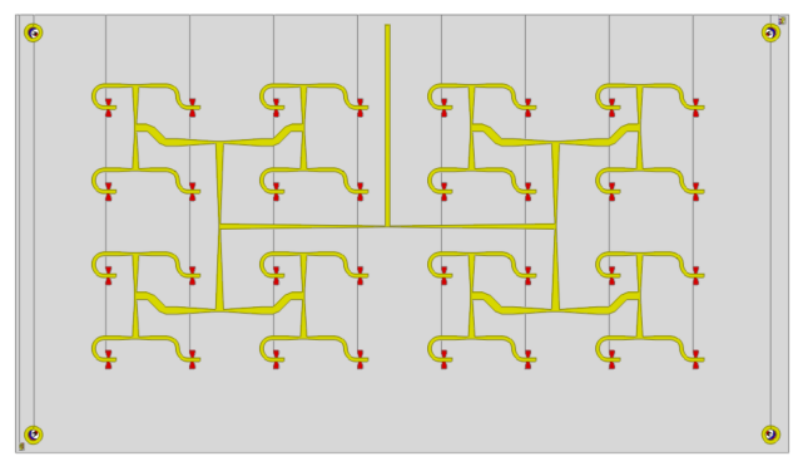

Şekil 7. 3 Boyutlu Besleme Ağının Alttan Görünüşü 


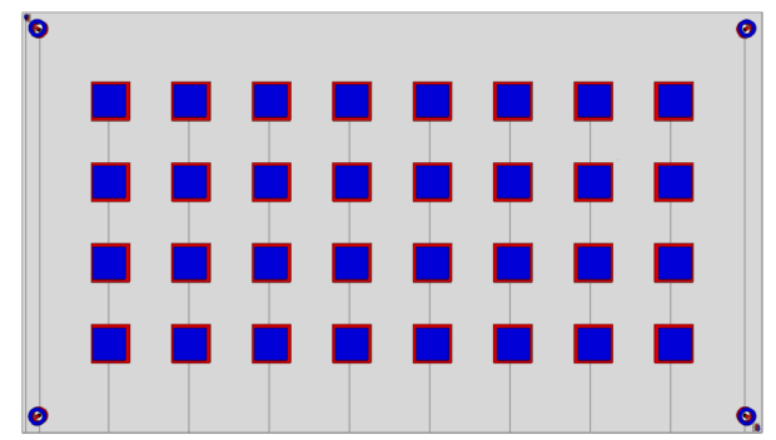

Şekil 8. 3 Boyutlu Besleme Ağı ve Anten Dizisinin Üstten Görünüşü

Yatay eksende 4 ve düşey eksende 8 tane olmak üzere anten dizisinin alttan ve üstten görünüşleri şekil 7 ve 8 de gösterilmiştir.

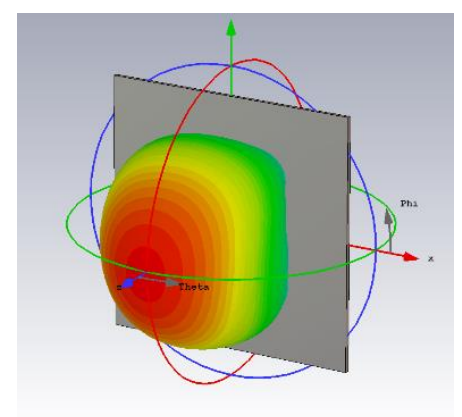

Şekil 9. Birim Antenin Işıma Paterni

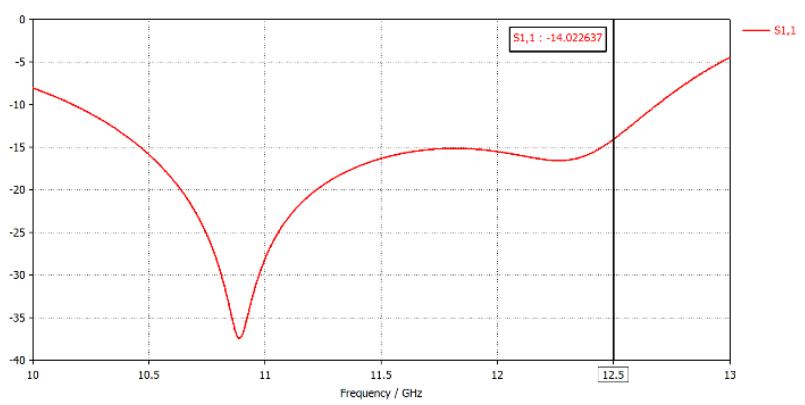

Şekil 10. Birim Antenin S Parametresi

Şekil 9 ve Şekil 10 tasarımı gerçekleştirilmiş birim antenin yönlendiriciliği 9.5 dBi'dır. Birim antenin giriş portundan görülen geri dönüş kaybı istenilen frekans bandında $-10 \mathrm{~dB}$ değerinin altında tutulmuştur.

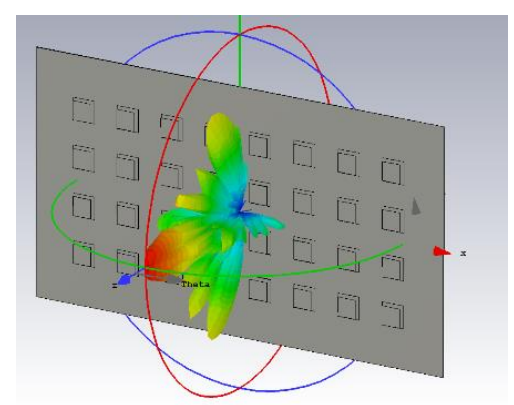

Şekil 11. Antenin Işıma Paternin Anten Geometrisi Üstünde Gösterimi

Birim antenden oluşturulmuş anten dizisinin 1şıma paterni Şekil 11'de gösterilmiştir ve yönlendiriciliği $24.3 \mathrm{dBi}$ değeridir. Yine aynı şekilde dizi antenin besleme ağıyla birleştirilmiş durumdaki giriş 
kapısındaki geri dönüş kaybı şekilde 10'da gösterilmiştir. Şekil 13'de Kartezyen koordinat sisteminde antenin yönlendiriciliği, ana lobun açısı ve yan lob seviyesi gösterilmiştir. Yan lob seviyesi $-10.3 \mathrm{~dB}$ seviyesindedir.

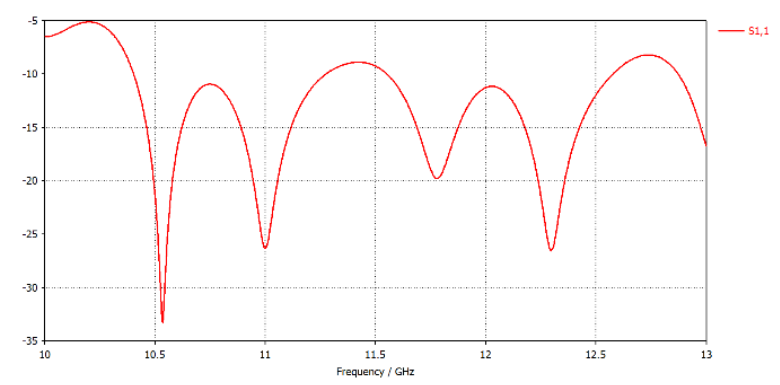

Şekil 12. Toplam Dizinin S11 Parametresi

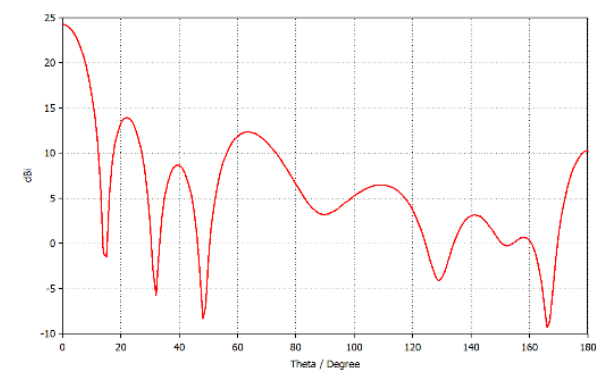

Şekil 13. Dizi Anten Kazancının Kartezyen Koordinatlarda Gösterimi

Dizi anten yapısının merkez frekans1 $12.8 \mathrm{GHz}$ olacak şekilde kazancı $24.3 \mathrm{dBi}$ ve yan lob seviyesi-10.3 dB olacak şekilde elde edilmiştir.

\section{Sonuç}

$\mathrm{Bu}$ çalışmada mikro şerit dizi anten besleme ağı tasarımı düşük dielektrik sabiti ve ince bir subsrat kullanılarak tasarlanmıştır. Besleme ağı yapısının S parametrelerinden sadece antene iletilen sinyalin genliği ve fazı ile ilgili bilgi vermektedir. Bundan dolayı besleme ağı yapısının dizi antenle birleştirip toplam olarak benzetim yapmanın gerekli olduğunu kararına varılmıştır. Bu yüzden dizi anten yapısı oluşturularak besleme ağıyla birleştirilmiştir. $\mathrm{Bu}$ sayede tasarlanan besleme ağının gerçek performansının gösterilmesi amaçlanmıştır. Besleme ağından kaynaklanan ışınım tipik olarak sistemin performansını düşüren bir etkidir. Diğer etki ise pürüzsüzlük faktörüdür. Pürüzsüzlük etkisi analitik olarak hesaplanıp, subsratın içine bir değişken olarak atanmıştır. Hâlbuki besleme ağından kaynaklanan ışınım analitik olarak bir ifadesi yoktur. Bu etki toplam dizi antenin 1şıma diyagramında kendini göstermiştir.

Mikro şerit hatlardan kaynaklanan dielektrik ve rezistif kayıplar besleme ağı yapısının performansını düşürmüştür. Buna rağmen toplan dizi anten yönlendiriciliği istenilen seviyede çıkmıştır. İleriki çalışmalarda daha ince subsrat kullanılarak ve daha düşük dielektrik sabitli subsrat kullanılarak besleme ağı yapısını tekrar gözden geçirilebilir. Mikro şerit hat kullanılarak tasarlanan besleme ağıyla belli bir anten sayısından sonra kayıp miktarı artmaktadır. Eğer dizi anten sayısını daha fazla artırmak isteniyorsa bunun için daha düşük kayba sahip bir iletim hattı seçmenin daha doğru olacağı düşünülmektedir. 


\section{Kaynaklar}

1. Balanis C.A. 2005. Antenna theory: analysis and design. 3rd ed, John Wiley, Hoboken, NJ. xvii, 1117 p, 783-875 pages

2. Mikulasek T., et al. 2016. Design of aperture-coupled micro strip patch antenna array fed by SIW for $60 \mathrm{GHz}$ band, IET Microwaves, Antennas \& Propagation, 10 (3): 288-292.

3. Carr J.J., Hippisley G. 2012. Practical antenna handbook. Fifth edition. ed., McGraw-Hill/TAB Electronics, New York, NY. xvi, 767 p, 149-175 pages.

4. İpekoğlu Y., Yücedağ O.M., Saraydemir S., Kocer H. 2015. Micro strip Patch Antenna Array Design for C-Band Electromagnetic Fence Applications, 9th International Conference on Electrical and Electronics Engineering (ELECO), 355-358.

5. Reynalda T., Munir A., Bharata E. 2011. Characterization of $4 x 4$ high gain micro strip array antenna for 3.3GHz WiMAX application, 6th International Conference on Telecommunication Systems, Services, and Applications (TSSA).

6. Ahmad, G. 2008. Design, Optimization and Development of X-band Micro Strip Patch Antenna Array for High Gain, Low Side Lobes and Impedance Matching, Second International Conference on Electrical Engineering.

7. Liu Y., et al. 2015. A Multi Beam Dual-Band Orthogonal Linearly Polarized Antenna Array for Satellite Communication on the Move, International Journal of Antennas and Propagation, 2015: $1-8$. 